\title{
The Influence of Hydroxylated Carbon Nanotubes on Epoxy Resin Composites
}

\author{
Jiaoxia Zhang, ${ }^{1}$ Yaping Zheng, ${ }^{2}$ Haijun Zhou, ${ }^{1}$ Jing Zhang, ${ }^{1}$ and Jun Zou' \\ ${ }^{1}$ School of Materials Science and Engineering, Jiangsu University of Science and Technology, Zhenjiang 212003, China \\ ${ }^{2}$ Department of Applied Chemstry, School of Natural and Applied Science, Northwestern Polytechnical University, Xi'an 710129, China
}

Correspondence should be addressed to Jiaoxia Zhang, myzjx@yahoo.cn and Yaping Zheng, zhengyp@nwpu.edu.cn

Received 23 July 2012; Accepted 7 November 2012

Academic Editor: Manish U. Chhowalla

Copyright (C 2012 Jiaoxia Zhang et al. This is an open access article distributed under the Creative Commons Attribution License, which permits unrestricted use, distribution, and reproduction in any medium, provided the original work is properly cited.

\begin{abstract}
Hydroxylated multiwall carbon nanotubes (MWNTs)/epoxy resin nanocomposites were prepared with ultrasonic dispersion and casting molding. The effect of hydroxylated MWNTs content on reactive activity of composites is discussed. Then the flexural and electrical properties were studied. Transmission electron microscope was employed to characterize the microstructure of nanocomposites. As a result, the reactive activity of nanocomposites obtained increases with the increasing content of MWNTs. When MWNTs content of the composites is $1 \mathrm{wt} \%$, as compared to neat resin, the flexural strength increases from $143 \mathrm{Mpa}$ to $156 \mathrm{MPa}$, the modulus increases from $3563 \mathrm{Mpa}$ to $3691 \mathrm{MPa}$, and the volume and surface resistance of nanocomposites decrease by two orders of magnitude, respectively.
\end{abstract}

\section{Introduction}

Carbon nanotubes (CNTs), since their discovery in 1991 [1], have generated huge activity in many areas of science and engineering due to their unprecedented physical and chemical properties [2-4]. The theoretical analysis and experimental investigation indicate that their extraordinary mechanical properties, the high chemistry stability, thermal stability, the good electric conductivity, unique nanometer effect, and so on make CNTs ideal for a wide range of applications such as nanoelectronics, nanomechanical system, electronic field launch, and sensor $[5,6]$. Especially CNTs are used to improve the mechanical and electrical properties of polymer because of the similar segmer structure between $\mathrm{C}-\mathrm{C}$ covalent bond of CNTs and polymer matrix. Due to the nonreactive surface of MWNTs, it is difficult to achieve efficient dispersion in a polymeric matrix. The realization of MWNTs reinforced polymer requires a homogeneous dispersion and strong interfacial interaction between MWNTs and the polymer. To address this problem, current work is in progress on noncovalent surfactant or polymer-wrapping modifications of MWNTs and on covalent functionalized utilizing openend and sidewall chemistry. In the recent years, researchers have made efforts on the surface modification to increase the properties of the polymer matrix composites [7-10].
Epoxy resin is a thermosetting epoxy polymer, which is used in a variety of applications because of its properties, such as thermal stability, mechanical response, and electrical resistance. In general, epoxy resins are known for their excellent adhesion, chemical and heat resistance, excellent mechanical properties, and electrical insulating properties [11, $12]$, but the curried epoxy resin by mixing with a catalyzing agent is brittle and the impact strength is lower. So it is necessary to toughen epoxy resin in order to extend its application [13].

In the present work, the hydroxylated MWNTs (MWNTS ${ }_{\mathrm{OH}}$ ) were added to the epoxy resin and sonicated to prepare $\mathrm{MWNTS}_{\mathrm{OH}} /$ epoxy resin nanocomposites. The gel time and curing dynamics of nanocomposites were studied, and their mechanical and electrical properties were also tested.

\section{Experimental Method}

2.1. Material. The hydroxylated MWNTs $\left(\mathrm{MWNTS}_{\mathrm{OH}}\right)$ used in this study were synthesized by chemical vapor deposition (CVD) and were provided by Chengdu organic chemicals CO., LTD. The average diameter of MWNTS $\mathrm{OH}_{\text {(hydro- }}$ xylated content: $3.06 \mathrm{wt} \%$ ) was about $20-30 \mathrm{~nm}$, the length was several micrometers, and the purity was $>95 \mathrm{wt} \%$. 
The MWNTS $\mathrm{OH}$ was used in our experiment without further purification. Epoxy resin 830 (epoxy number of $0.56-$ $0.61 \mathrm{eq} / 100 \mathrm{~g}$ ) was produced by Wuxi Di'aisheng epoxy resin CO., LTD. Aromatic hardener (JHB-590) with an acid value of 660-685 mgKOH/g was produced by Dalian-Jinshi Chemical Industry. The formula is 75 parts of hardener by 100 parts of epoxy resin.

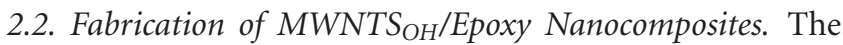
$\mathrm{MWNTS}_{\mathrm{OH}}$ was added to the epoxy resin at $80^{\circ} \mathrm{C}$ in order to lower the viscosity of the epoxy resin. Filler weight fractions ranging from $0 \mathrm{wt} \%$ to $5 \mathrm{wt} \%$ were dispersed in the epoxy resin and were sonicated $(1200 \mathrm{~W}$ ultrasonic cell disruptor) for 1 hour. After cooling to room temperature, the hardener was added to the homogenous mixture and was compounded for another $30 \mathrm{~min}$. The resulting mixture was then taken into a preheated steel mold coated with the mold release agent. The mold enclosed resulting mixture was degassed at $80^{\circ} \mathrm{C}$ under vacuum for $30 \mathrm{~min}$ to remove bubbles. The mixture was cured at $80^{\circ} \mathrm{C}$ for 1 hour, followed by $3 \mathrm{~h}$ at $120^{\circ} \mathrm{C}$ and another 3 hours at $140^{\circ} \mathrm{C}$ to complete the crosslink reaction.

2.3. Measurements. MWNTS $\mathrm{OH}_{\mathrm{H}}$ dispersion in the epoxy matrix was observed through transmission electron microscope (TEM Hitachi (Tokyo, Japan) H-800). The film samples with a thickness of $1 \mu \mathrm{m}$ of the MWNTS $\mathrm{MH}_{\mathrm{H}}$ /epoxy nanocompsites were prepared by ultramicrotome cutting.

Differential scanning calorimetry (DSC) traces were collected using Q1000 TA instruments at a heating rate of $10^{\circ} \mathrm{C} / \mathrm{min}$.

The gel time was carried out by plate-spinning method. The mixtures were put into the plate at specified temperature to obtain the interval of time required for a colloidal solution to become a semisolid jelly or gel.

The flexural properties were measured using a universal testing machine under the three-point loading scheme (GB/ T2571-1995) and the sample size is $80 \mathrm{~mm} \times 15 \mathrm{~mm} \times 4 \mathrm{~mm}$. Ten specimens of each nanocomposite were tested and the mean values and standard deviations were computed.

The volume and surface resistance were measured by Ultrahigh resistance $\left(10^{17}\right)$ and microcurrent $\left(10^{-14}\right)$ testing instrument (ZC36), and sample size was $100 \mathrm{~mm} \times 100 \mathrm{~mm}$ $\times 4 \mathrm{~mm}$.

\section{Results and Discussion}

3.1. The Influence of $M W N T S_{O H}$ on the Gel Time of Nanocomposites. The gel time reflects effect of temperaturedependent activity of system. In this process, the influence of $\mathrm{MWNTS}_{\mathrm{OH}}$ contents on the gel time of the epoxy resin according to different temperatures was tested (shown in Figure 1). It showed that the gel time of $\mathrm{MWNTS}_{\mathrm{OH}} /$ epoxy resin nanocomposites decreased with the increase of the MWNTS $_{\mathrm{OH}}$ content. In addition, the gel time tends to be consistent at higher temperature and is the shortest when the MWNTS content being 5\%. It indicated that $\mathrm{MWNTS}_{\mathrm{OH}}$ accelerated the curing reaction and enhanced the reactivity of epoxy resin at low temperature. That may relate to the

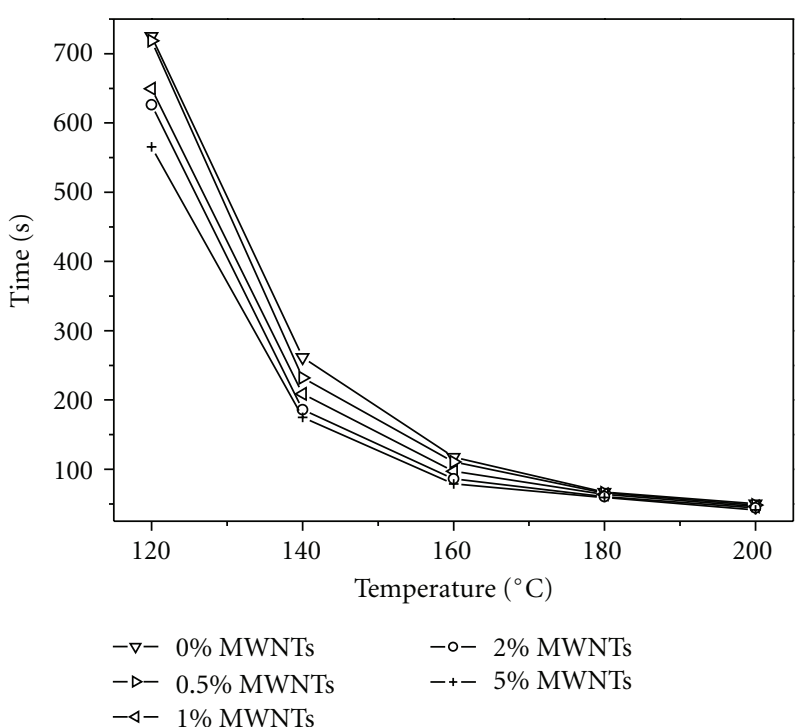

FIGURE 1: Gel time of $\mathrm{MWNTS}_{\mathrm{OH}} /$ epoxy resin nanocomposites versus temperature.

TABLE 1: The influence of MWNTS $\mathrm{OH}_{\mathrm{H}}$ on the thermal properties of nanocomposites.

\begin{tabular}{lcccc}
\hline MWNTS $_{\mathrm{OH}}$ content $/(\%)$ & $T_{i} /\left({ }^{\circ} \mathrm{C}\right)$ & $T_{f} /\left({ }^{\circ} \mathrm{C}\right)$ & $T_{p} /\left({ }^{\circ} \mathrm{C}\right)$ & $\Delta H /(\mathrm{J} / \mathrm{g})$ \\
\hline 0 & 118.70 & 190.63 & 151.78 & 268.6 \\
0.5 & 117.37 & 188.94 & 150.68 & 297.1 \\
1 & 116.46 & 187.07 & 149.98 & 301.0 \\
2 & 114.01 & 186.13 & 149.55 & 311.0 \\
5 & 110.52 & 183.13 & 148.09 & 331.2 \\
\hline
\end{tabular}

hydroxylated group on the surface of $\mathrm{MWNTS}_{\mathrm{OH}}$ which participates in the curing reaction of epoxy resin system.

3.2. The Influence of $M W N T S_{\mathrm{OH}}$ on the Thermal Behavior of Nanocomposites. DSC was used to characterize the thermal properties of MWNTS $\mathrm{MH}_{\mathrm{H}}$ epoxy resin nanocomposites. The reaction enthalpy $(\Delta H)$ was obtained by the area integration between DSC curve and baseline with $\mathrm{J} \cdot \mathrm{g}^{-1}$ as unit. Figure 2 and Table 1 show the process of curing reaction of $\mathrm{MWNTS}_{\mathrm{OH}} /$ epoxy resin nanocomposites with different contents of $\mathrm{MWNTS}_{\mathrm{OH}}$. It was shown that the peak temperature $\left(T_{p}\right)$ decreased, but the $\Delta H$ increased. It further explained that the reactive activity increased, so the curing reaction is easy to occur at lower temperature. It was clear that the self-catalyzed reaction of epoxy resin is evoked by hydroxy. The hydroxylated groups on the surface of MWNTS $_{\mathrm{OH}}$ participate in the reaction of epoxy resin to decrease the temperature of reaction and increase the cross linking reaction leading to an increase in the $\Delta H$.

3.3. The Influence of $M W N T S_{\mathrm{OH}}$ on the Flexural Properties of Nanocomposites. The flexural strength and flexural modulus of epoxy nanocomposites with various addition ratios of $\mathrm{MWNTS}_{\mathrm{OH}}$ were described in Figure 3. It showed that when the content of $\mathrm{MWNTS}_{\mathrm{OH}}$ is $1 \%$, its flexural strength increased from $143 \mathrm{MPa}$ to $156 \mathrm{MPa}$ and their flexural 


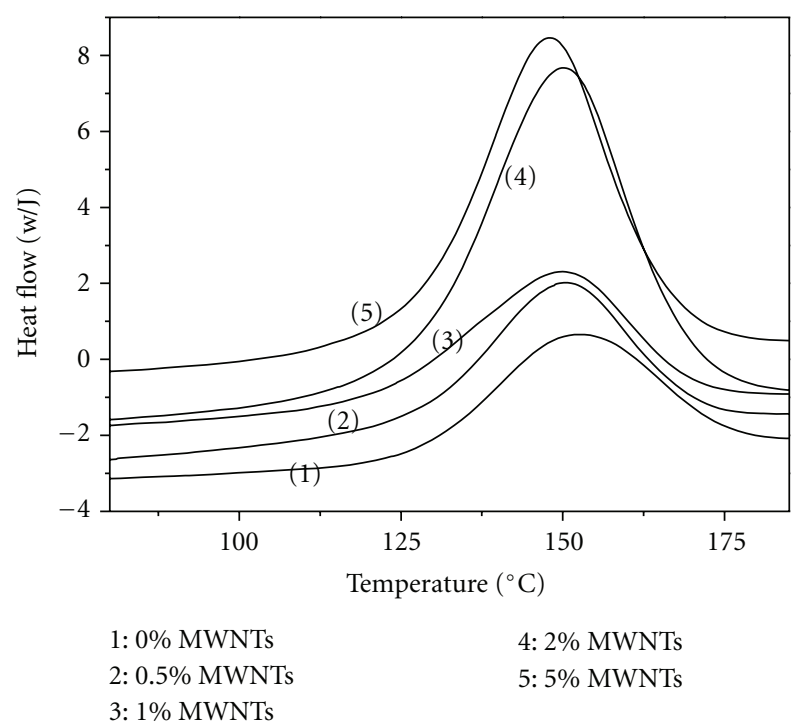

FIGURE 2: The influence of $\mathrm{MWNTS}_{\mathrm{OH}}$ on the thermal properties of nanocomposites.

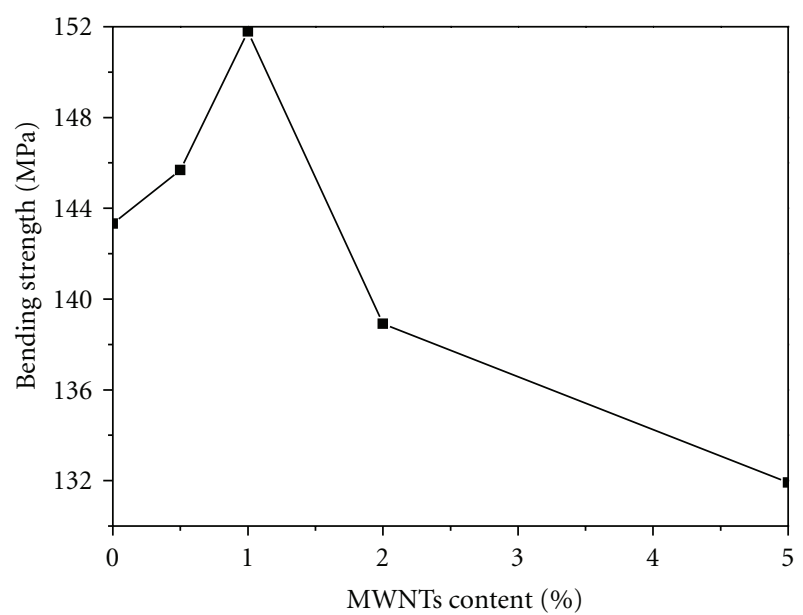

(a)

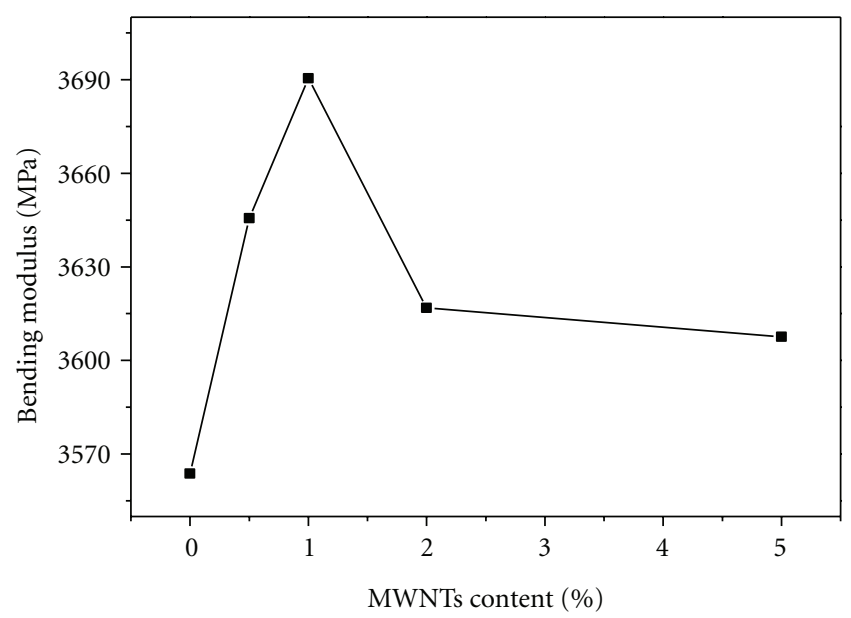

(b)

Figure 3: The influence of $\mathrm{MWNTS}_{\mathrm{OH}}$ on flexural properties of nanocomposites ((a) bending strength, (b) bending modulus).

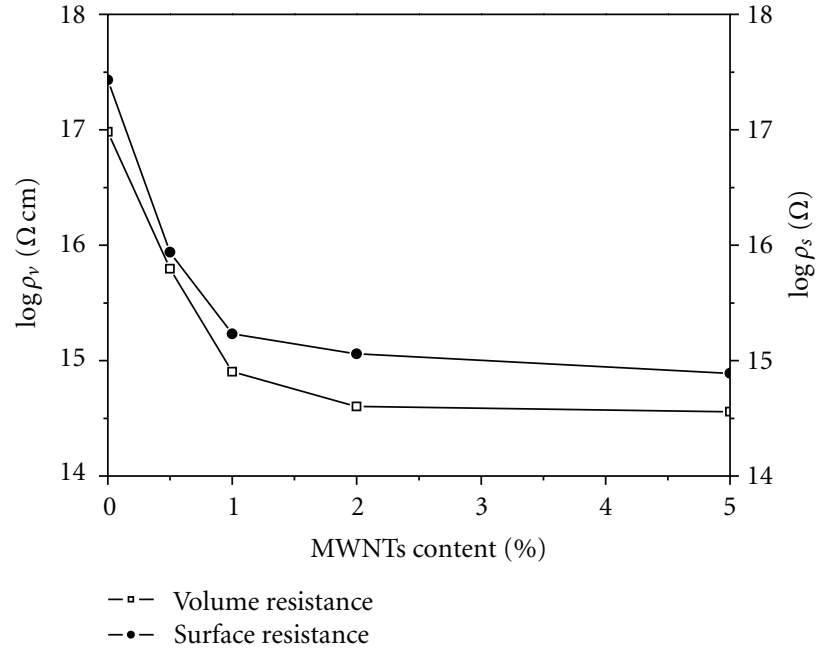

FIGURE 4: The influence of $\mathrm{MWNTS}_{\mathrm{OH}}$ on the electrical properties of nanocomposites.

modulus can be improved from $3563 \mathrm{MPa}$ to the maximal value of $3691 \mathrm{MPa}$, as compared to neat resin. The group of $-\mathrm{OH}$ on the surface of $\mathrm{MWNTS}_{\mathrm{OH}}$ participates in the curing reaction and forms fine interfacial bonding between matrix and $\mathrm{MWNTS}_{\mathrm{OH}}$. In addition, a microforce of mutual locking is produced, the unsaturated dangling bonds on the outer wall leading to the formation of chemical bonds, and Van der Waals force between the MWNTs and substrate can play an important role to evenly disperse MWNTs and enhance the bending property [14].

When the content of $\mathrm{MWNTS}_{\mathrm{OH}}$ increased further, flexural properties of nanocomposites decreased. The less efficient improvement at higher contents is attributed to an increasing amount of observed agglomerates that cannot effectively transfer outside force. The locale agglomerate formed stress point leads to the generation of fracture source, which decrease the mechanical properties [15]. Furthermore, the $\mathrm{MWNTS}_{\mathrm{OH}}$ is cut and the length of $\mathrm{MWNTS}_{\mathrm{OH}}$ becomes short due to the strong ultrasonic power that damages the properties of MWNTs, so the effect of improvement of mechanical properties is reduced (see Figure 5).

3.4. The Influence of $M W N T S_{\mathrm{OH}}$ on the Electrical Properties of Nanocomposites. The application of conductive nanoparticles in the polymer matrix is supposed to decrease the electrical resistance. The experimental results of the nanocomposites are shown in Figure 4. The volume and surface resistivity decrease with the increase of $\mathrm{MWNTS}_{\mathrm{OH}}$ contents. When the content is $2 \%$, the value of volume and surface resistivity drop by two orders of magnitude. The formation of good conductive circuit of $\mathrm{MWNTS}_{\mathrm{OH}}$ in polymer matrix improves the electrical properties of composites. The charge carrier MWNT moving in the material leads to conduct in the nanocomposites. However, because the length of MWNT became shorter in the ultrasonic process, the volume and surface resistivity decrease lower than the previous reports [16]. That is consistent with the result of Feng et al. [17] that the aspect ratio has influence on the electric conductivity. 


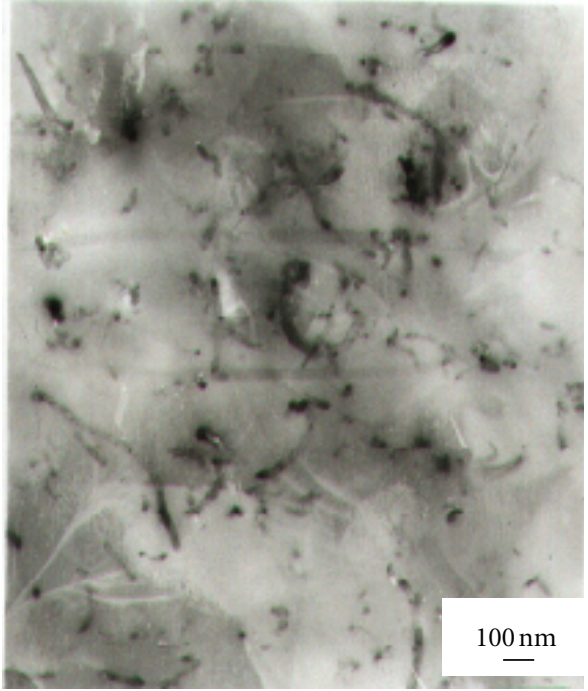

(a)

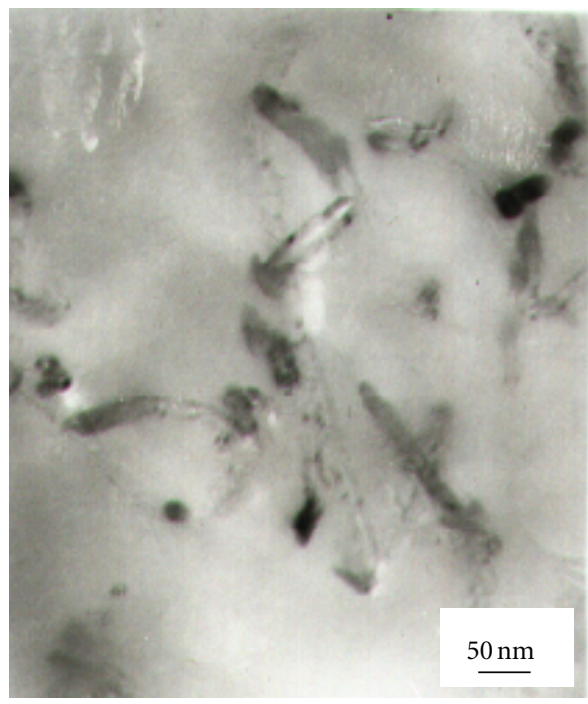

(b)

FIgURE 5: The TEM images of MWNTS $_{\mathrm{OH}} /$ epoxy resin nanocomposites.

3.5. The Microstructure of $M W N T S_{O H}$ in Epoxy Matrix. Figure 5 is the TEM image of $\mathrm{MWNTS}_{\mathrm{OH}}(1 \%)$ in epoxy matrix, and the black line is the dispersed $\mathrm{MWNTS}_{\mathrm{OH}}$. There is not agglomeration phenomenon in the polymer matrix because the hydroxyl groups on the surface $\mathrm{MWNTS}_{\mathrm{OH}}$ have good compatibility with epoxy resin. The shorter high aspect ratio shown in Figure 5 with about $30 \mathrm{~nm}$ diameter and $100 \mathrm{~nm}$ length also improves the dispersion but damages the mechanical and electrical properties that further lead to the improvement of properties of nanocomposites being decreased.

\section{Conclusion}

The $\mathrm{MWNTS}_{\mathrm{OH}} /$ epoxy resin nanocomposites were prepared by melt mixing. There is a homogeneous dispersion in polymer matrix of $\mathrm{MWNTS}_{\mathrm{OH}}$ through ultrasonic treatment. So $\mathrm{MWNTS}_{\mathrm{OH}}$ improves the reactive activity and increases the flexural and electrical properties of composites, whereas the shorter high aspect ratio damages the flexural and electrical properties of $\mathrm{MWNTS}_{\mathrm{OH}}$ which make the improved affectivity of composite's properties reduced to a certain extent.

\section{Acknowledgments}

The authors greatly acknowledge a project funded by the Priority Academic Program Development of Jiangsu Higher Education Institution, the Key Laboratory Funded by Jiangsu advanced welding technology, the Starting Research Fund (635061201) from the Jiangsu University of Science and Technology, and Jiangsu Provincial Natural Science Foundation of China (Grant no. BK2012279).

\section{References}

[1] S. Iijima, "Helical microtubules of graphitic carbon," Nature, vol. 354 , no. 6348 , pp. 56-58, 1991.

[2] S. Iijima and T. Ichihashi, "Single-shell carbon nanotubes of 1nm diameter," Nature, vol. 363, no. 6430, pp. 603-605, 1993.

[3] D. S. Bethune, C. H. Kiang, M. S. de Vries et al., "Cobalt-catalysed growth of carbon nanotubes with single-atomic-layer walls," Nature, vol. 363, no. 6430, pp. 605-607, 1993.

[4] J. N. Coleman, U. Khan, W. J. Blau, and Y. K. Gun'ko, “Small but strong: a review of the mechanical properties of carbon nanotube-polymer composites," Carbon, vol. 44, no. 9, pp. 1624-1652, 2006.

[5] H. M. Cheng, Carbon Nanotubes Synthesis, Microstructure, Properties and Applications, Chemical Industry Press, Beijing, China, 2002.

[6] J. Q. Wei, X. F. Zhang, and K. L. Wang, Carbon Nanotubes Macrostructure, Tsinghua University Press, Beijing, China, 2006.

[7] Y. J. Li, K. L. Wang, J. Q. Wei et al., "Improving tensile properties of double-walled carbon nanotube strands by intercalation of epoxy resin," Carbon, vol. 44, no. 1, pp. 176-179, 2006.

[8] Z. Yang, X. H. Chen, Y. Q. Liu et al., "Study of carbon nanotubes methylolated and grafted with maleic anhydride," Acta Chimica Sinica, vol. 64, no. 3, pp. 203-207, 2006.

[9] C. X. Bian, X. C. Xu, G. G. Yang et al., "Study on conductive mechanism of composites-sulfonated polyphenylacetylene/Multiwalled carbon nanotubes," Acta Chimica Sinica, vol. 65, no. 6, pp. 525-531, 2007.

[10] Z. Yaping, Z. Aibo, C. Qinghua, Z. Jiaoxia, and N. Rongchang, "Functionalized effect on carbon nanotube/epoxy nanocomposites," Materials Science and Engineering A, vol. 435436, pp. 145-149, 2006.

[11] L. Yuan, X. Y. Ma, and Y. Wang, "Study on development of toughening epoxy resins," Polymer Bulletin, vol. 6, pp. 8-12, 2003.

[12] S. N. Hsu, L. J. Chen, and S. C. Wu, "Annealing behaviors of dislocation loops near the projected range in high-dose $\mathrm{As}^{+}$implanted (001)Si," Journal of Applied Physics, vol. 68, no. 9, pp. 4503-4507, 1990.

[13] Y. P. Zheng, R. C. Ning, and Y. Zheng, "Study of $\mathrm{SiO}_{2}$ nanoparticles on the improved performance of epoxy and fiber 
composites," Journal of Reinforced Plastics and Composites, vol. 24, no. 3, pp. 223-233, 2005.

[14] A. Star, J. F. Stoddart, D. Steuerman et al., "Preparation and properties of polymer-wrapped single-walled carbon nanotubes," Angewandte Chemie-International Edition, vol. 40, no. 9, pp. 1721-1725, 2001.

[15] G. M. Yuan, X. K. Li, M. J. Zhang, Z. S. Lv, and G. D. Zhang, "Effect of carbon nanotubes on the mechanical properties of epoxy resin," Aerospace Materials \& Technology, no. 2, pp. 3841, 2005.

[16] Y. P. Zheng, Q. H. Chen, L. X. Chen, and R. C. Ning, "Study on carbon nanotube/epoxy nano-composites," Polymer Materials Science \& Engineering, vol. 22, no. 4, pp. 216-218, 2006.

[17] Y. C. Feng, M. Z. Qu, G. M. Zhou, B. L. Zhang, and Z. L. $\mathrm{Yu}$, "Study of the carbon nanotubes application to conductive coatings-(I) effects of the carbon nanotubes on the electrical conductivity of conductive coatings," Polymer Materials Science \& Engineering, vol. 20, no. 2, pp. 133-135, 2004. 

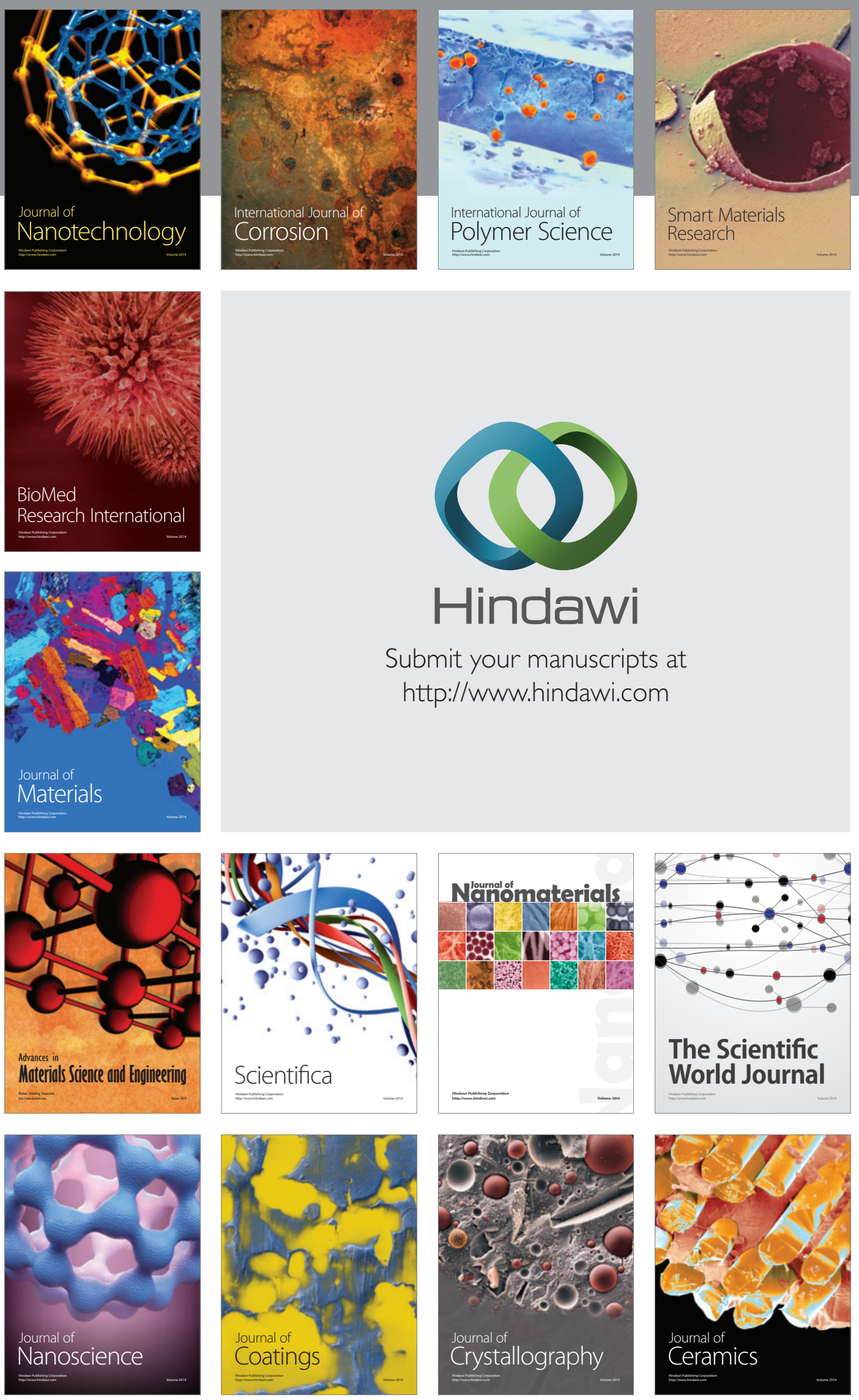

The Scientific World Journal

Submit your manuscripts at

http://www.hindawi.com

\section{World Journal}

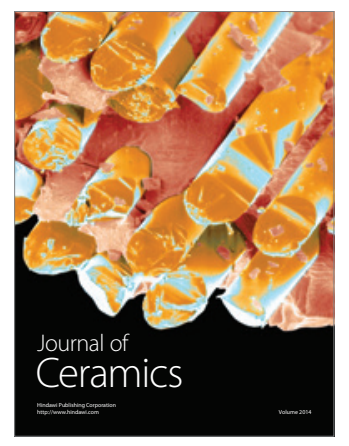

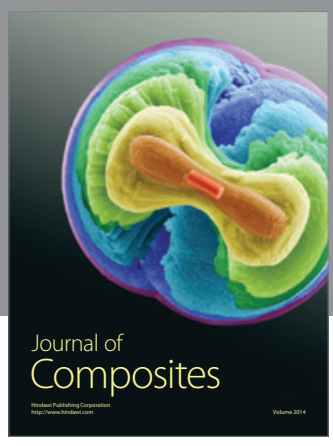
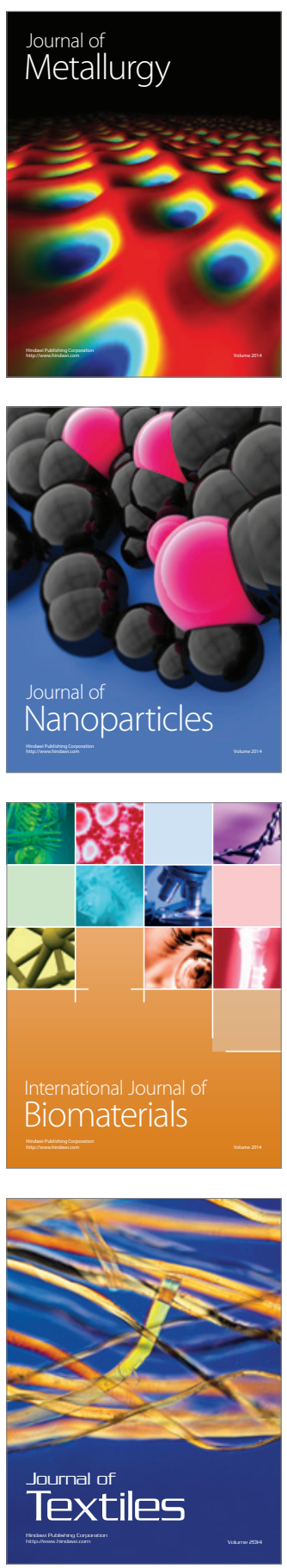